\title{
The Complicit Therapist
}

Complicities offers a theory, not a therapeutic practice, but if it is taken in as a way of understanding human being, it will inevitably affect practice, as it will affect how the therapist knows what she is doing in her work, and why. And there are practices that take into account the theory of human being I have described under the rubric of complicity. In this chapter, I will detail the established ways of working that help us to apply the theory of human being I have explicated. In addition to Internal Family Systems (IFS), which understands each one of us as a system of parts carrying reactions to our experiences in the world, I will briefly explore the role of neurobiological implications for psychotherapy practice through interpersonal neurobiology (IPNB) and polyvagal theory. I will also look at how attachment theory intersects with these somaticbased ideas. Complicities is nothing if not a systems theory, but a systems theory that brings also the notion of the fold. We are not working with black boxes or binaries, but with complex, rhizomatic relations between self and other, constitutive relationships between inside and outside. History, both personal and community history, matters to the system's functioning. I have also referred to intersubjectivity throughout this book, and I will return to it as a useful frame for practice. 
If subjects are best thought of as rhizomes or assemblages that "metamorphose or change their properties as they expand their connections" (Rose, 1998, p. 172) and not as binary structures based on self/other or subject/object, then we have a model, following Rose (1998) and Butler (1997) (who both follow Foucault), for understanding subjectification as a process embedded in regimes of power and the realities they enable. This model is responsive to the implications of attachment theory and IPNB, which demonstrate the subject's reliance on their context, including people, to be a subject. We are so far from the Cartesian lone ego. We are, in fact, imbricated on each other physiologically, vulnerable to and dependent on relationship. If there is a core to human being, that is it. Attachment theory and IPNB also illustrate the places where therapy comes in: with a physical understanding of how and why the therapist is complicit in the client's healing. This will be described in more detail below.

A complicit approach might also be seen to bring a set of values to psychotherapeutic practice. I have often been uncomfortable with the conflation of a social justice orientation with the right to judge clients, or when a client's hour is talked about as an opportunity to do advocacy work, as I have heard at some conferences for therapists with a social justice awareness. Advocacy work for a better world is important and admirable, but in my opinion, it is different to the job of a therapist, which is to hold space as nonjudgmentally as possible. IFS would say nonjudgmental acceptance is the necessary prelude to change. We all have parts that act out in rage or shame or hatred or fear. Understanding those parts and what they are trying to protect is the first step toward enabling them to transform their roles. Rage, shame, hatred and fear are burdens. Judging them is not helpful.

Of course this does not mean that we are objective. What it does mean is that if there are issues, attitudes or types of people we cannot or do not wish to tolerate, it is our responsibility not to work with those types of people or those issues or attitudes. Otherwise, in my opinion and in my practice, my job is to help clients understand themselves, in the shaping context of a relationship with me. As should be clear by now, this means also working together on understanding context-family systems; childhood experiences; what specific relationships are doing and what clients are doing in them; identity; culture and histories. The last moving piece 
is what happens relationally between a client and my own person-and/ in-context. So a complicit mindset is a value system that brings together a theory of what human being is, as outlined in this book, and an approach to therapeutic work that takes seriously what nonjudgment means: We are none of us innocent, and we are all of us implicated in each other. I say a little more about this toward the end of this chapter.

The history of psychotherapy has marked a gradual coming together of two different approaches. One is the intrapsychic model of psychoanalysis, which at its start was concerned only with what was happening inside the client (it has since evolved, as the concept of the intersubjective third makes clear). The other is the systems approaches of community mental health and family therapy, developed partly in reaction to psychoanalysis's initial repudiation of context on the inner life of the individual psyche. A theory of complicity shows us that both models need to be taken into account, as each exists in and because of the other. In this chapter, I will account for how I think about the work I do, beginning with my idea of my role, my therapeutic stance. For me, this is feminist.

\section{Stance}

Rose (1998) details how one of the signature markers of a scientific approach is the assertion of objectivity. This value-or perhaps, more accurately, fiction-was also an informing element of classic psychoanalysis, although as mentioned above, a more sophisticated understanding of the role of the therapist's personhood is now mainstream in psychoanalysis (see Cooper, 2007). But the idea of the therapist as expert, and thereby as possessed of a scientifically endorsed objective take on a client's person, is still an informing power dynamic of the psy disciplines. This power dynamic is enforced by institutional encroachments on clients' lives and identities, especially for clients who are queer, BIPOC, indigenous, poor, trans, disabled, or at the intersections of these or other othered identities and social positions. The institutional power of the psy expert draws its authority from the history of psychology as outlined in Chap. 1, where the discipline emerged from and helped underwrite a series of related social forces, including colonialism, patriarchy, liberalism 
and capitalism. Psychoanalysis, a major force in the emergence of psychology as a mainstream discourse of self-understanding, also played a role, deploying a complex jargon which helped create an insiders' club, and having an original vision of the therapist as both patriarch and expert (ask Freud's client Dora, Bernheimer \& Kahane, 1985).

Feminist therapy has been around since the 1970s, and started responding to and integrating with existing therapeutic approaches through the 1980s (Dankoski \& Deacon, 2000; Hare-Mustin, 1978; Williams, 1995). Reviewing definitions of feminist therapy from this time period, Dankoski and Deacon (2000) summarize that feminist therapy: recognizes the historical and ongoing fact of women's oppression, which by now I would expand to include all gender oppression as I detailed in Chap. 4, as well as intersectionality; works to understand and change gender oppression; brings social context into intrapsychic models; and challenges binary gender norms. In its evolution, it has had to account for transnational and decolonial dynamics, and evolve to accommodate majority world needs and knowledges (Boonzaier \& van Niekerk, 2019; Collins et al., 2019). In its Western origins, feminist therapy was more collectively formulated than many other approaches (Sang, 1995), although like white feminism in general, it needed to learn to be properly inclusive. It currently still needs to account for its relationship to hegemonic, WEIRD-driven academic psychology and to transexclusionary ideologies.

Feminist therapists are committed to "a non-hierarchical relationship... [and] empowerment" of clients (Dankoski \& Deacon, 2000, p. 53). Many first-generation feminist therapists recount the experiment with informational equality in the early days of feminist therapy, where the therapist abandoned the stance of objective expert and engaged as a co-partner, including self-disclosing to address the power imbalance in the relationship. The general conclusion seems to be that respecting the relationship as an unequal one in terms of both institutional power and emotional disclosure is more advantageous (Robbins, 1995). In other words, the feminist therapist has an ongoing responsibility to acknowledge the power she has in the relationship, while also affording clients mutuality, respect and basic human, given she cannot grant institutional, equality. 
Therapeutic healing is also connected to the acknowledgment that external power dynamics affect the client, and that social change is also needed to address individual suffering (see Herman, 1997). Thus, in all its complexity, it is the therapist's job to engage with power dynamics not only in the therapeutic relationship, but also in clients' lives. There is an acknowledgment that context affects and structures psyches (Dankoski $\&$ Deacon, 2000).

In other words, being a feminist therapist means acknowledging that we are not objective experts, because, being human, we all have standpoints that inform what we can see and how we understand the world and each other (Brown, 2018). It also means acknowledging that in the systems which have formed modernity, including psychotherapy, there are always power relations that need to be acknowledged and worked with. This entails recognizing injustice. As feminist therapist Greenspan (2017, p. 335) puts it, "We live in the world, and the world lives in us. It's not too far from this awareness to becoming a radical feminist activist." Brown (2018, p. 40) provides a framework for identifying power dynamics in "four realms... somatic, intrapersonal/intrapsychic, intrapersonal/social-contextual, and spiritual/existential, all in constant exchange and interaction." She (Brown, 2018) suggests that a feminist therapy understands that client distress comes from disempowerment in one or more of these realms, and not from individual pathology.

If we have an awareness of power dynamics at all levels of all systems, as well as the understanding that intersectionality and, and in, context, always matters (Zerbe Enns et al., 2020), we can acknowledge the limits of our knowledge and understanding. In this way, we also acknowledge that the client is an expert of their own experience. The feminist therapist's job is to hold the awareness of the limits of her knowing in openness, curiosity and respect, to allow the creation of a mutually enabling and respectful third space (on which more below).

In all these ways, feminist therapists are not objective scientific experts. At the same time, as therapists we bear the bulk of the responsibility for the therapeutic relationship. Holding this responsibility with awareness of our own complicit humanity I hope allows us (at least in our best moments) to be fully human in the room, and to tolerate our own limits and imperfections. Then we can better accompany our clients. 
A feminist stance is against neutrality, which does not recognize power relations and does not, to my mind, work with the attachment component of the therapeutic relationship. A stance of neutrality can be withholding, even cruel. It certainly works to keep the therapist safe. But then, I am not by nature someone to sit back. Accordingly, I work to find the balance between holding space for the client's questions, concerns, feelings and experiences, and being present as myself. In psychotherapeutic practice, this process can sometimes be put in the language of directive or nondirective approaches or styles. I would suggest that a complicit therapist recognizes there is really no such thing as being nondirective. By being present with a client, we direct change, as the neurobiological theories detailed below explain. Even holding space, or unconditional positive regard, as a main intervention is engaging complicitously, because we are human. We are implicated in each other on all systems levels, and therapy is an intimate connection. It is far more of a poetry than a science. Indeed, to make the point again about the inadequacy of binaries, neuroscience proves that human being is poetic.

\section{Trauma-Informed, Body-Based Theories}

Psychotherapists are applied neuroscientists. (Cozolino, 2010, p. 341)

Interpersonal neurobiology tracks the physiology of complicity, showing how mind, body and brain are formed in relation to the minds, bodies and brains of others (Solomon \& Siegel, 2003). IPNB is interdisciplinary (Siegel, 2019). Like the psychological humanities, it recognizes that we have to get outside of silos of knowledge in order to understand the full picture of human being. Like the notion of complicity, it is all about the constitutive role of connections in the making of personhood. Somatic therapy practices like Somatic Experiencing (SE) therapy or Hakomi therapy, and body-based understandings of emotional states like Polyvagal Theory, show how emotional experiences of self and other are carried in the body, and exactly how the body's knowledge helps form the brain and mind (Kurtz, 2007; Payne et al., 2015; Porges, 2018). Together these approaches help us understand how all kinds of trauma, from 
single-incident PTSD to complex or developmental traumas to attachment woundings, shape an individual's internal system. More generally, they show how relationships shape us biologically. They demonstrate how individual systems co-relate, co-regulate, and co-create each other. Each individual is also a self in larger sociocultural and historical context, connected rhizomatically to other individuals, as I have been arguing. Each individual is also a self in a body, whose expressions are personal, cultural, familial and interconnected. Each autonomic nervous system and the mind it helps create is complicit in a network of others, known and inherited.

In the last few decades of the twentieth century, some academics and practitioners of psychology began to integrate neurobiological findings into their theories of human affect, exploring how we can physiologically map the ways our early years help form our subjectivities: "Both the brain and the self are built in a stepwise manner by experience" (Cozolino, 2010, p. 31). Furthermore, our minds are co-created with other minds, and are not co-terminous with our brains; we are both "mind-as-brain activity and mind-as-relational activity" (Siegel, 2019, p. 225). And the two are complicit in each other in networks of nested systems that force us to include others and the so-called outside world in each one of us, and in the therapy process.

These scientists and physicians offered theories to account for why therapy works. They married attachment theory and the awareness of processes of somatic co-regulation and the physiological, and therefore emotional and cognitive, consequences of interpersonal interactions. The constitutive role of social systems in creating a nervous system that can feel safe and work well shows us how early and ongoing reactions in the body help set the terms for the mind's sense of itself (Cozolino, 2010; Porges, 2018; Siegel, 2019; Van der Kolk, 2014).

Explicating the constitutive energies between brain, mind, relationships with others and relationships with bodies (our own and the body of the other), IPNB and other theories that explore the interweavings of self and others on a physiological level has illustrated complicity at work in the process of therapy (Afford, 2020; Badenoch, 2008; Schore, 2012). Right brain processes, body-based experiences and unconscious awareness are valued over cognitive and behavioral-based models (McGilchrist, 
2009; Schore, 2003). Together with IPNB, this marks a "paradigm shift in psychotherapy practice towards the acknowledgement of the value of non-verbal, implicit processes in the clinical setting" (Peña, 2019, p. 102). Psychoanalysis accommodates this awareness and has been integrated with a neurobiologically driven theory of human being (Schore, 2012).

We know now, therefore, that nonverbal, right brain, affect-based communication is a crucial component of self (Afford, 2020; McGilchrist, 2009; Schore, 2003); that "the body keeps the score" in ways the conscious mind cannot remember (Van der Kolk, 2014); that there are "intersubjective origins of the implicit self" (Schore, 2012, p. 34); and that, "actions are automatic and adaptive, generated by the autonomic nervous system well below the level of conscious awareness... These are autonomic energies moving in patterns of protection" (Dana, 2018, p. 6). This last point, which focuses on the role of the autonomic nervous system in generating unconscious responses to implicit or perceived threat, based on previous trauma to the client's social bonding system, comes from Polyvagal Theory (Porges, 2018):

Polyvagal Theory demonstrates that even before the brain makes meaning of an incident, the autonomic nervous system has assessed the environment and initiated an adaptive survival response. Neuroception precedes perception. (Dana, 2018, p. 6)

Neuroception describes the out-of-awareness work done by the autonomic nervous system, based on its expectations of the world. Neuroception sets the terms of possibility for a client's sense of self and other. This is one way the past lives within each of us, and helps shape the present. The process of co-regulation via the ventral vagus-linked social engagement system (Dana, 2018) is one way the therapeutic relationship can help change a client's neuroceptive responses. Polyvagal theory works well with attachment theory and its mapping of attachment styles, which, based on early relational experiences, set the terms for what we expect from the world and how we implicitly experience others. Polyvagal theory also works with trauma-informed therapies and with somaticinformed approaches (Levine, 2018; Ogden, 2018; Van der Kolk, 2018). Together, they help fill in the details of both why and how the past, 
including the people in past relationship with the client; the present and its stimuli and triggers; and the therapist's self (with its past and present formative markers and responses), are all complicit in and with the client.

Early childhood experiences occur before the prefrontal cortex is developed, and are experienced on a physical level. They are encoded in the brain as preverbal understandings. Before we develop the capacity for language and for explicit memory recall, we come to know things literally via our bodies and the sensations they communicate to us (Bretherton, 1992; Langer, 2019; Schore, 2003; Siegel, 2003; Stern, 1985). This knowledge is stored in implicit memory. This is one way that our early contexts are inscribed on and in our subjectivities. From a relational point of view, Harris (2009, p. 178) explores a child's dependence on their first caregivers in a way which makes clear there is no reclaimable self before attachment:

A developmental account of identity formation must elaborate the dialectical and paradoxical idea that self, including a gendered self, emerges from an interaction in which the child is already interpreted, experienced, and understood. The experience of being mirrored becomes an inextricable element in the child's internal self-schemas in a way that forever blurs the distinction between an experience's beginning inside or outside.

So we are made by the way we are treated and how it feels in our bodies. (Langer, 2019 has pointed out the implications for transgender humans in a symbolic system that assumes cisgender human being unless explicitly told otherwise.) These early interactions with others set the terms by which we know who we are, what to expect from the world, and how and why to relate to others. These are the terms of attachment theory, of course:

Originating in an amalgam of psychoanalysis and behavioral biology, attachment theory... posits that the real relationships of the earliest stages of life indelibly shape us in basic ways, and... attachment processes lie at the center of all human emotional and social functions. (Schore, 2012, p. 27; see Karen, 1994) 
IPNB confirms this. This interdisciplinary marriage brings together a psychoanalytic awareness of the formation and consequences of the unconscious; a systems thinking understanding of the constitutive importance of context and the power of relationships to set the terms for individuals; and somatic and polyvagal understandings of how emotions are encoded in the body and implicitly in the brain, outside of prefrontal cortex awareness and control.

As therapists, we treat this by bringing our own selves to interact with the client's dysregulated, frozen or traumatically fragmented inner system (Afford, 2020; Badenoch, 2008). We have to bring our bodies and our limbic systems, as much as, or perhaps even more than, our scientific inquiring minds: "psychotherapy is not the 'talking' but the 'communicating' cure" (Schore, 2012, p. 39). The notions of the intersubjective and of the internal family system have a role to play in understanding and feeling our way through this therapeutic process, and each will be addressed in more detail below. Understanding that the therapist's sense of self is the guiding framework for the therapy process is a complicit feminist awareness. It means we cannot see ourselves as above or outside what is going on. We cannot assume the scientific, objective expert position. We are together with each client.

The therapist's right brain interacts with the client's right brain, outside of awareness and outside of and beyond language. In order to engage with and help heal a client, we literally do physical, feeling work with them (Afford, 2020; Badenoch, 2008; Geller \& Porges, 2014). This is a fully complicit engagement, not only between participants but in the therapist's embodied stance too.

It follows that, in order to be as fully physiologically, implicitly available as possible for the interpersonal process, that therapist is ideally available to themself first. In IPNB terms, the therapist's own brain is integrated, allowing for a flexible mind; and in IFS terms, explored below, the therapist works best when in Self. This means knowing as much as we can about our own minds; countertransferential triggers, in psychoanalytic terms. In his explication of the neuroscience of psychotherapy, Cozolino (2010, p. 30) writes, 
Each therapist-client pair creates a unique system resulting in a particular outcome... [T] he therapist's unconscious contributes to the context and outcome of therapy... [T [herapists... will be putting their imprint on the hearts, minds, and brains of their clients.

Knowing our own complicit systems is step one. Learning what we can about our client's is step two. To do this we use both our minds and our bodies, listening to information from both on their varied and connected (complicit) levels. This has been put in terms of the neurobiological role of clinical intuition, and the knowledge that gut feelings connect via the autonomic nervous system to right brain processes and implicit memorybased understandings that are embodied (Peña, 2019). Understanding that our system and our clients' interrelate-that therapy creates intersubjective space which is biological as well as psychic-is the final step, and it is in this space that therapy happens. I hope it can be seen how this frame, which connects different approaches, makes use of both science and the art of psychotherapy (Schore, 2012); indeed, understands that they work together, or not at all.

Cozolino (2010, p. 46) suggests "a number of working hypotheses" generated from considering the neuroscientific underpinnings of a range of psychotherapeutic modalities, from depth work to systems work to cognitive behavioral approaches. These are, first, that intellectual (left brain, prefrontal cortex) understanding of a problem without (right brain) integration of feelings and sensations cannot bring about psychological change: "Whether it is called symptom relief, differentiation, ego strength, or awareness, all forms of therapy are targeting dissociated neural networks for integration" (Cozolino, 2010, p. 46). This process requires a therapist who is empathetically attuned to the client's spoken and unspoken experience, resulting in secure attachment (see also Afford, 2020; Geller \& Porges, 2014). It is also reliant on the leveraging of "optimal stress" (Cozolino, 2010, p. 46), or what SE therapy calls working with the window of tolerance: emotions must have room to be safely felt and contained in the therapeutic process, and "[a]ll forms of successful therapy strive to create safe emergencies in one form or another" (Cozolino, 2010, p. 46). The resulting experience creates opportunities to change autobiographical memory, aka conscious sense of self, as well as 
the body's unmetabolized memories of the past (Van der Kolk, 2014): "psychotherapy involves changes not in the cognitions of the patient's... mind/brain... but in the affective embodied experiences of his or her [or their] brain/ mind/ body" (Schore, 2012, p. 12).

Schore (2012, p. 10) describes the implications of the findings that early childhood experiences shape the brain and mind, and that right brain affective processes may be more important than left brain cognition in understanding and treating mental health:

Previously the Cartesian mind/ body split has plagued not only psychology and psychiatry but medicine in general... The current paradigm shift in research from cognition to emotion has been a major force in resolving the Cartesian problem and generating theoretical models that integrate... "nature and nurture."

Schore (2012, p. 16) also suggests that modern culture has become too invested in and reliant on left brain processes, resulting in,

[A]n overemphasis on psychopharmacology over psychotherapy, an undue influence of the insurance industry in defining "normative" and "acceptable" forms of treatment, an overidealization of "evidence-based practice", an underappreciation of the large body of studies on the effectiveness of the therapeutic alliance, a trend towards "manualization" of therapy, a training model that focuses on the learning of techniques rather than expanding relational skill...

These critiques should be familiar to the reader by now, along with their social, historical and economic complicities. It is worth noting that these are all the same complaints made about the consequences of viewing psy work as a science, explored in Chap. 1. Schore (2012) invokes McGilchrist's (2009) warning of the development of a technocratic, neoliberal world order, also as a consequence of ignoring the importance of right brain, affective, embodied and interconnected elements of human being, as explored in Chap. 5.

From his work on the importance of the implicit, affective experience of self in the formation of later, thinking, self-awareness, and the neuroscientific evidence behind this explanation of how the unconscious works, 
Schore (2012, p. 119) concludes, "The concept of a single, unitary 'self' is as misleading as the idea of a single, unitary 'brain." Porges (2018) suggests the brain is also in the body; and Schore's (2012, p. 119) work shows how the self begins in the preverbal right brain: "The left and right hemispheres process information in their own unique fashion" and comprise two systems, conscious and unconscious. There is no Cartesian unity here, not even on a physical level (see McGilchrist, 2009). If there is one modality that most embraces the idea of the self as a collection of parts, which takes into account systems thinking, depth work and somatic experiences, it is Internal Family Systems.

\section{Internal Family Systems}

Internal Family Systems (IFS) is both a way of understanding human being and a therapy modality. It was developed by Richard Schwartz out of family therapy approaches to clients with eating disorders (Schwartz \& Sweezy, 2020). IFS has been shown to be effective with a range of clients, individual, couple and family groupings, and a range of diagnoses (Haddock et al., 2016; Lucero et al., 2018; Sweezy \& Ziskind, 2017). It has been demonstrated to significantly improve the ability to mentalize and perspective-take (Böckler et al., 2017) and has been recognized by the National Registry of Evidence-based Programs and Practices as an evidence-based treatment for anxiety, depression and medical conditions (Matheson, 2015; Schwartz \& Sweezy, 2020; Sowell, 2013). It has also been extensively used in therapy with survivors of childhood sexual abuse (Goulding \& Schwartz, 2003).

IFS counters the mainstream Western idea of the unified self, explored in Chap. 1, by understanding subjects as made up of a collection of parts, as well as a core Self who has the innate, organic capacity to lead the system. There are two broad categories of parts, protectors and exiles, with the latter carrying the burdens of unmetabolized emotions and traumatic, horrifying or hurtful experiences.

IFS offers a sophisticated view of how systems are made up of complicit relations. It applies systems thinking, which traces relational patterns and sees a system as self-organized, complex and striving toward health: 
Systems thinking helps us examine the various systems surrounding or within a client to find and release constraints. Constraints may exist in a client's system of inner personalities, in the client's relationship with various family members, in the way the family in general is organized, in the way various institutions outside the family affect it... and in the way the client's ethnic community and the larger society affect the families values and beliefs. All of these human systems are interlocked. They affect and are affected by each other. (Schwartz \& Sweezy, 2020, p. 26)

Furthermore, attest Schwartz and Sweezy (2020, p. 26), these systems mirror each other structurally at each level. There is thus "a good deal of universality" in the operating principles across systems. This framing, as we will see, allows IFS to envision its model of parts with roles that can go awry as applicable to all levels of human being and the institutions that structure our outer, and therefore help to structure our inner, lives.

IFS assumes that our parts always work for us, even if they sometimes are at odds with each other (as when one part of you wants one thing, and another part wants the opposite), or are doing counterproductive work (such as internally shaming a person to try and keep them safe from revealing a shamed part). This is a way of understanding binary positions as polarizations between two parts, which are invariably working at loggerheads for the same thing. The solution is not to take sides, but to facilitate understanding between the parts - to break the binary energy that is keeping them both stuck and escalating in relation to each other.

IFS is nonpathologizing, seeing symptoms as the behaviors caused by parts that need to be heard and understood. It is each person's unique, intrinsically healing Self that does the hearing and helping of component parts. The therapist is a guide, not an expert-how can she be expert about someone else's internal system?

The IFS process entails finding, identifying and listening to parts. Parts can be held in places in the body, and can also be frozen in a traumatic moment in time. As such, IFS offers a practice that understands and makes use of the insights of both depth and systems psychotherapies, as well as the techniques of somatic psychologies that understand how the past can be held in the body, and from there, impact the psyche. 
This offers an understanding of the ecological relationship not only internally but between people and their wider systems. It is a fundamentally complicit understanding of human being, bringing an awareness of how systems both form and impact each other, as well as an optimistic, empowering view of the systemic striving for health:

$[\mathrm{H}]$ uman systems - parts, individuals, families, communities, and cultures-nest, mirror, and interact. And since all systems sustain injury at times, all are at risk of developing burdens that can be passed down for generations. At the same time, all systems seek balance and make attempts to self-right. (Schwartz \& Sweezy, 2020, p. 228)

Schwartz and Sweezy (2020, chapter 18) apply IFS to American society, and their findings echo the assessments made in Chaps. 2 and 3 here. They suggest that America carries legacy burdens of racism, patriarchy, individualism and materialism (what I have named as capitalism), all of which were brought by Europeans fleeing not only persecution, but a culture that brutally controlled and punished its members (Foucault graphically details these methods of control in Discipline and Punish Foucault, 1977). They also account for Trumpism in an interesting way, as a rigid, protective defense against economic changes of the past 40 years.

In this way, the IFS understanding of how systems work, sometimes maladaptively, to protect and maintain the status quo, layers onto historical explanations for the development and maintenance of binary systems. It also offers an alternative psychological model to the psychoanalytic self/other understanding as to why this culture has developed the processes of toxic othering that have driven value systems and the institutions that perpetuate them:

The American legacy burdens of racism, patriarchy, individualism and materialism imbue protectors with... contempt. As a result, the United States not only exiles a greater percentage of its population than any other Western nation, it has less compassion and more contempt for its exiled populations. (Schwartz \& Sweezy, 2020, p. 246) 
Parts work goes well with the understanding of neural networks and the habits of being they set up and can be changed by (Badenoch, 2008). IPNB's focus on the complex system that makes up our selves-or, indeed, in IFS's term, Selves-includes the expectation that the system strives toward harmonious self-organization, which means health is achieved through flexibility and integration of systems (i.e., systems work smoothly together) (Siegel, 1999). Anderson (2013, p. 108) suggests that working with parts "can create the optimal environment for the brainstem, limbic system, cortex, and especially the prefrontal cortex to work together, promoting neural integration and creating new pathways in the brain." In other words, there may be a neurobiological explanation for how and why IFS works, which includes the interpersonal forces detailed by Siegel $(1999,2007)$ and the nonverbal, embodied right brain processes tracked by Schore (2003) and by somatic-based psychotherapies like Hakomi (Kurtz, 2007) and Somatic Experiencing (Levine, 1997; Payne et al., 2015). Anderson (2013) suggests that IFS helps implicit memory become explicit, integrates experience and creates new neural networks to enable new responses to situations, stimuli and people. Thus, IFS works with aspects of trauma theory which trace the ways trauma is encoded in the body (Van der Kolk, 2014). He (Anderson, 2013, p. 109) also proposes that certain reactive parts 'live' in the brainstem or amygdala, and that "over time... we will learn where all the parts are located in the brain."

In my experience, IFS's nonjudgmental, nonpathologizing approach to whatever a client is experiencing is not only appealing for a feminist therapist, it is extremely effective. As Schwartz (2017) commented in a discussion about working with racist parts as a white man, hating our parts has never worked in getting them to change. Learning to know our parts is a powerful way to understand how our internal systems work, because it allows us to see the internal connections, alliances, arguments we have going on and how these structure our responses and reactions to ourselves and others. It sees binaries as unhelpful oppositions to be mediated and resolved, so that co-operation is possible between parts. It also accounts for the impact of external systems of all kinds on the experiences and reactions of specific parts. Because IFS is collaborative in approach, it fits with a feminist stance. It does not expect the therapist to be the 
expert; it wants to hear from the parts. Crucially, also, IFS's main goal is to support a client's Self in taking leadership internally. IFS allows the therapist and the client to problem-solve together. While trust in the therapist is an important enabling component of this approach as all others, mutuality is a value in IFS (Schwartz, 2013).

IFS is not a system of object relations in the psychoanalytic sense. It takes parts literally, not metaphorically or symbolically, or as introjects. Intersubjectivity, as it is developed in psychoanalysis, begins by interrogating the classic psychoanalytic self/other binary, where the other is both an internalization used by the self, and, crucially, in need of recognition as an independent subject, not just material for object relations.

\section{Beyond the Self/Other Binary: Thirdness}

If IFS sees parts as literally independent entities or subpersonalities that are in relation to the Self (we are made up of others who are also ourselves), intersubjective psychoanalytic psychotherapy aims to own the self's dependence on the other. Here the other is both outside of, and then introjected into, the self. In this sense, it is a part. Crucial to the intersubjective understanding is the recognition that the other-the literal outside person upon whom the subject is dependent, in the first place the mother or first caretaker-is also a self. The object in object relations theory is thus restored to its own humanity, from whence comes its power and importance as internalized object in the subject's psyche. The self craves the other's recognition, which means the self needs the other to be also a self, and not just an object (Benjamin, 1988). This breaks the objectifying power of binary energy, and, as Benjamin (1988) points out, the constituting logic of patriarchy's rules for personhood, where the female is the first object on which the self depends.

Benjamin (1995) details how the self needs to hold the other both as its own independent self, and as an internalized other. Locating oneself between these two places of the other is necessary to respect the other's personhood as well as to inhabit one's reliance on the other, she says. This fundamentally nonbinary understanding of human being is what Benjamin (1995, p. 5) calls an "ambiphilic" approach. She explores the consequences 
of asking about the difference between other as another subject (a "real" object) and other as internalized part (an object relation), while acknowledging that "both are endemic to psychic experience" (p. 29). "Intersubjectivity was formulated in deliberate contrast to the logic of subject and object, which predominates in Western philosophy and science" (Benjamin, 1995, p. 30). Thus, she insists on a both-and approach.

This nonbinary approach facilitates the embrace of the intersubjective as the space where therapy occurs. The therapist's self is complicit in the process, and in the client's experience of self through the therapist as other. This third space, between and because of the dyad of two selves in the relationship, is constituted through body-based and right brain, affective, nonverbal communications (Schore, 2012). To add Benjamin's $(1988,1995)$ intersubjective vocabulary and perspective to this process, the client must experience the therapist as an independent subject in order to benefit from their healing presence, while at the same time taking the therapist in to facilitate a different sense of self, of what is possible inside and in relation, and therefore, to change. Once more, the complicit nature of human being - the ways our minds rely on and make each other-is core to the therapy process theoretically as well as actually, in physical reality. The focus becomes squarely relational, on attachment processes and the feelings of love, safety, recognition and pleasure that occur when selves embrace all aspects of their complicities. Gesturing toward the consequences of viewing self as self-contained, Benjamin (1995, p. 32) comments, "The idea of pleasure was lost when ego psychology put the id on the backburner, but it might be restored by recognizing the subjectivity of the other." Benjamin's (1995) definition of pleasure is pleasure in and of mutuality. It is a result of the relation between two selves, which means the rejection of the self/other binary.

The interpersonal neurobiological intersects with the idea of the creation of a third as the result of the relation between two, a model of nonbinary human complicity that describes what therapy is:

The social synapse is the space between us... When we smile, wave, and say hello, these behaviours are sent through the space between us via sights, sounds odors, and words. These electrical and mechanical messages received by our senses are converted into electrochemical impulses within our 
brains. These signals stimulate new behaviors, which, in turn, transmit messages back across the social synapse. (Cozolino, 2010, pp. 179-80)

Afford (2020) tracks in detail how this interpersonal neurobiology works in the therapy room. What does an online, mediated world, as explored in Chap. 5, do to this necessary human interaction? And what has the past year of largely online therapy conducted under the shelterin-place rules of life during the coronavirus pandemic done to our work? What will it mean if we choose to continue virtual living once coronavirus is more contained? What will the cyborg third feel like? Certainly, Benjamin's (1995, pp. 36-7) articulation of the risk of intersubjectivity speaks to some of the relational consequences this culture is seeing in a socially mediated world:

The need for recognition entails this fundamental paradox: at the very moment of realizing our own independent will, we are dependent upon another to recognize it. At the very moment we come to understand the meaning of $I$, myself, we are forced to see the limitations of that self. At the moment when we understand that separate minds can share similar feelings, we begin to learn that these minds can also disagree.

Ideally, we learn ultimately to tolerate the spectrum of differences between self and self, from different needs, to disagreement to conflict. We need the self not to become an objectified other, which Goulding and Schwartz (2003, p. 46) describe as the "distorted" results of polarization, where another's multiplicity is lost to the extreme reaction of a triggered part. For the other to retain their personhood in the face of conflict or disagreement, a state of "constant tension between recognizing the other and asserting the self" must be possible (Benjamin, 1995, p. 38). It is not a resting place. It is a place of ongoing doing, which requires us to manage the "sting" (ibid, p. 47) of having to engage with, manage, accommodate, speak back to, see, difference. Rather than use the other as an object to secure the borders, the stability, of the self, which is the typical use of otherness in Western colonial, patriarchal self/other psychology.

In the description above, Benjamin (1995) is tracking a developmental process in the young child: If he can learn to see his mother as a person, 
he can learn to tolerate her difference from him. Then he will not need to control her to feel safe. Elsewhere she (Benjamin, 1988) details how, in a patriarchal culture, the refusal of mutual recognition and the establishment of a sense of self built on the other as object set up relations of domination. The first object, in such a culture, is the mother, and the subject is the child of Freud's Oedipus complex, detailed in Chap. 2. Sexual difference becomes the lynchpin of the system. Patriarchy intersects with racism, with colonialism and with the neoliberal capitalism that resulted from the historical outspooling of all three, together with the centering of the self-contained, dependency-rejecting, left-brainvalorizing Cartesian subject as the model for Western subjectivity. Othering, cancelling, entrenched partisanship: what are these if not an inability to tolerate the subjectivity of the other? And if mutuality requires an embodied component, it is no wonder that a society increasingly built on social media is struggling to cohere as a society. As detailed in Chap. 5 , my contention is that the computer age, late modernity, has exacerbated many of the dynamics of early modernity, whence began the modern systems of domination with all their consequences for human being across a globe subjected to Western norms.

The idea of the intersubjective third also includes social, political and historical dynamics, as we saw in Chap. 2. Sehrbrock (2020) calls this social thirdness, and writes about how therapists should manage the intersubjective consequences of what he calls prejudice, which creates two subjects locked in their own positionality with regard to each other. Attention to the social third-the space made of the collective and the cultural as well as the interpsychic - is crucial, according to Sehrbrock (2020), to avoid reproducing the silencing imperatives of homophobia and misogyny, and other prejudices. This is one way to understand how a social justice commitment enters clinical practice without becoming an imposition of therapist values on the client:

Attention to the social third, to me, is thus a clinical and ethical obligation of exercising social conscience.... by silencing or ignoring the subtle and gross intersectionalities of social thirdness, psychoanalytic practice perpetuates the very injuries and pains it purports to heal. (Sehrbrock, 2020, p. 291) 
His conclusion: "In order to realize psychoanalytic principles in the age of \#MeToo, Time's Up, and BlackLivesMatter, we need to recognize social thirdness as an aspect of our conscience, our ethics, and our psychoanalytic politics" (Sehrbrock, 2020, p. 294). Stephens (2020) explores how the intersubjective process of knowing ourselves with and through the other can help with long-standing racialized dynamics in Western culture. An intersubjective approach, she (Stephens, 2020) suggests, can counteract the binary dynamics in self/other thinking that perpetuate dynamics of oppression and the typical affective responses of guilt and rage.

As I have been illustrating, the therapy process is an interaction between two embodied, contextualized minds. The intersubjective space, itself existing in context, is reliant on right brain, affective, intuitive, nonverbal, embodied relating between client and therapist (Peńa, 2019; see Afford, 2020). In exploring the implications of intersubjectivity for a Western psychology rooted in a self-contained 'I', and intuiting IPNB, Coelho and Figueiredo (2003, p. 195) ask:

But is it in fact possible to perceive what the other self feels, what it perceives? We assume that in some way it is, since psychological practices are based on elements of perception, and especially on mutual perception. Possibly most communication depends on a sophisticated interplay between the perceptions of the participants in the therapeutic process... There are pre-verbal, infra-verbal, pre-representational, corporal and perhaps even instinctual forms of communication, as well, of course, as verbal communication itself. There are conscious, pre-conscious and, who knows, perhaps even unconscious perceptions. Why not? We often transmit what we do not know we have perceived, and also recognize sensations and feelings whose origin we are unsure of. We recognize our own feelings, but are they really ours, or the other's?

IPNB answers the first question posed here ("is it in fact possible to perceive what the other self feels?") with a resounding "yes," and also explains how. We not only perceive the feelings of the other, through various channels of communication, as Coelho and Figueiredo (2003) detail above, but we can account for the ways the feelings of the other not only resonate within, but help to constitute, the self, physically as well as psychically. 
Thus, working in the intersubjective space means working with the lessons of the somatic-informed therapy practices. It also means working within a systems focus, because culture, history and inheritances are an inevitable part of the space, within and between each participant, therapist and client. IFS therapy calls some of these inheritances, the ones that cause or carry trauma in the broad sense, burdens. It looks to see which parts of both therapist and client hold and respond to burdens, in order to help free them of their constraining roles. All of these approaches can be understood as acknowledging and responding to the fact of complicity as the fundamental marker of human being. They merely approach this fact in their own, often complementary and intersecting, ways.

\section{A Social Justice Practice}

How to engage in a discipline, psychotherapy, that stands accused, as we have seen, of co-creating the oppressive systems of modernity? How does the therapy space take full account of the social third if therapy itself is a force of Foucaultian discipline and subjectification? Despite the ongoing work of liberation psychologies, critical psychology, feminist and decolonial psychologies, psychology remains a powerful proponent and cause of binary thinking, and often reliant on the stance of scientific objectivity, with all the objectifying dynamics we have traced so far. Psychotherapy stands accused of helping to invent and perpetuate the liberal subject, today neoliberally subjected by all the institutions of the Western world.

Psychoanalysis offered the insight that the subject is a subject by virtue of its alienation from itself, and therefore cannot be the imagined masterfull, self-centered, liberal subject the West believes it to be. This has been very productive for literary theory, but less transformative of mainstream psychotherapeutic practice. In 2021, with the ongoing dominance of behavioral medicine and under the influence of the healthcare industrial complex, the psy disciplines remain "the very heartland of the self" (Rose, 1998 , p. 8), helping to perpetuate the idea that, if we can afford it, we are responsible for ourselves, and for improving so as to be productive citizens of late capitalism. Rose (1998) argued that no one theory of the human subject (such as psychology) could account for the process of 
subjectification in which such theorizing participated. He reminds us to pay attention to the "complex of apparatuses, practices, machinations, and assemblages within which human being has been fabricated" (Rose, 1998, p. 10). Given that the humanities at least has known this for decades, what do we do now, in a Trumpified, burning, melting, drowning, contagious world? What can psychology do, given its complicity in the creation of this world?

For example, Binkley (2020) writes about the emotional postures of black rage and white listening, and how together they serve to reinforce white privilege. He details his personal experience of trying to understand his ambivalence about being invited to occupy the position of white listener, in an "unholy contract" of "raging and listening... sustaining and enriching each other, wedded in a conspiracy to keep me where and who I was, and to suppress any possibilities for an overturning of things as they were. Or imagining things as they might be" (Binkley, 2020, p. 93). He offers a genealogy of these raced emotional positions as they exist in liberal institutions. He suggests that the expressions of strong emotion as catharsis, met with an empathetic listening, are psychologized technologies: ignorant white privilege learns to know and transcend itself via an empathetic encounter with the rage of the raced other. Responsible listeners learn their own authentic personhood and how to undo racism. The result is,

Where once the politics of race might have been about conflicting ideas, structural analyses, and moral commitments, today it is about empathetic sensibilities, emotional states, and the capacity to sense and respond to what others around you are feeling. (Binkley, 2020, p. 93)

If Binkley is correct, this suggests that the current state of resistance to racial injustice is individualized and psychologized through the modernizing, political, processes mapped by, for example, Rose (1998) and Sugarman (2020). In being individualized, this process is rendered binary, and reduced to a self/other relation that by definition will always need someone to despise. This someone is as easily the listening white as it is the constitutive other of privilege's invisible self. It is the inadequate cis feminist or the ignorant rich kid. It allows progressive culture to fragment itself. 
The feeling of being trapped Binkley describes is familiar to me, as a well-intentioned white person who is committed to interrogating the comforts of my privilege and resisting the collapses of fragility. I am not rendering structurally equivalent the oppressed subject of institutional inequality and/or structural oppression, and the well-intentioned listening white. But I am suggesting that the same binary structure, when it is the essentialized model for accounting for oppression, can undo our chance for real systemic change. Historically, oppression in Western modernity operates along a self/other binary, where the constitutive other is made to bear the self's projections so that the self can experience itself as good and whole and in control. To counter such a structure, we need a different model. We need a theory of the complicit subject, where innocence or guilt, goodness or badness, cannot be the focus. Furthermore, we need to think in more complex ways about where the language of psychology, and particularly ideas of wounding, trauma, rage, guilt, and intention have left us. To do this, we do would do better to challenge the idea of individual subjects locked in positions of privilege versus positions of victimization.

In tracking her evolution as a feminist therapist from social activist, aware of the importance of context to each human, to a more profoundly connected understanding of human being through what she calls the dark emotions, Greenspan (2017, p. 342) writes of "a new paradigm of emotional ecology in which our seemingly most personal emotions are connected to their larger social and global contexts." Goodman and Freeman (2015, p. 9) call for the need to "think otherwise" in psychology. To reject the bounded self of modernity, of liberal individualism, is to embrace a self open to what it does not know, which is to say, the world outside itself. For Goodman and Freeman, such a psychotherapeutic practice is "more relational" and, implicitly therefore, "more ethical." And that, finally, is what the idea of the complicit subject offers: an ethics of "being-with" (Goodman \& Freeman, 2015, p. 9) that might help us engage with the systemic injustice that harms us all.

None of this is intended to downplay the inheritances of race, class, gender, religious, geographic, cis-privilege or ablebodied-privilege. I am not trying to excuse or ignore the abuses of power on which the neocolonial world is built. I am certainly not resisting the recent public discourse 
about privilege, especially white privilege, which is finally being heard by at least some white people thanks to the hard and careful work of the Black Lives Matter movement. America is built on the exploitation and suffering of Native, Black and brown people, and those foundations cannot be dug up. Western culture is built on a cisgender binary that informs all its systems of thought and meaning. It is also true that until white people and cisgender people and ablebodied people and people assigned male at birth and those with class privilege can bear to take responsibility for these foundations, outrage remains appropriate. But outrage, however painful and true its source, is easier than holding the complexity of complicit, flawed humanity. This includes learning to understand and accept all of our parts, and how they—and we-are reliant on each other.

This is one suggestion for how we truly make space for the other, what it means to hold therapeutic compassion, perhaps especially for those very different from ourselves. A theory of complicity is at odds with identity politics and the binary positionings identity politics have unfortunately sometimes come to reinscribe. Identity politics are necessary for visibility within a liberal system, as explored in Chap. 2, and also bring important self-affirming, empowering possibilities in the context of Western individualism, allowing for solidarity in the face of oppression and the concomitant negation of personhood suffered by so many. But basing a program for change on a way of thinking that defines us all according to our place in the current structure, and from there, in binary relation to each other, has its limits, in terms of ways forward out of the system. We have seen how, in political science, Brown (1995) has written about this, and from gender studies, so has Butler (1993). Gamson (1995, p. 391) also explores the paradox that in America, "fixed identity categories are both the basis for oppression and the basis for political power." In another example, this time from the discipline of history, Scott (1991) explores the importance and the implications of making visible homosexual practices and the institutions that enabled them, as a project of reclaiming a denied history:

History is a chronology that makes experience visible, but in which categories appear as nonetheless ahistorical: desire, homosexuality, heterosexuality, femininity, masculinity, sex, and even sexual practices become so many 
fixed entities being played out over time, but not themselves historicized. (Scott, 1991, p. 778)

Thus, "The project of making experience visible precludes analysis of the workings of this system and of its historicity; instead, it reproduces its terms" (Scott, 1991, p. 779).

Scott (1991) acknowledges the importance, for someone who has experienced marginalization, of visibly experiencing oneself as part of a mass of people like oneself, of belonging to a movement, for both identity and political safety. Such movement processes allow challenges to what were previously master narratives of normality and moral goodness, which either left out or used (othered) the experiences and identities of marginalized groups. Counter-narratives, the right to make one's own meaning of one's self, life, desires and group, are powerful and important pushbacks against oppressive meanings being made of one and one's group.

At this point in history, some of us are more free of powerful institutions claiming the right to decide about who we are, who we should be and what is to be done to us to make it so. So-called conversation therapy, the attempt to change sexual orientation or gender identity, is now illegal in a number of states (Drescher et al., 2016; Newhook et al., 2018). One consequence of postmodernity, however, is that evidence becomes always partial-there can no longer be absolute proof of one absolute truth, since the postmodern reality is one of fractured, competing, different stories, narratives of and about difference. In a binary frame, difference always means power dynamics, and so meanings are contested. One result, writes Scott (1991, p. 777), is that "experience" becomes an underwriter of historical evidence, of the truth of someone's reality:

It is precisely this kind of appeal to experience as uncontestable evidence and as an originary point of explanation-as a foundation on which analysis is based-that weakens the critical thrust of histories of difference.... these studies lose the possibility of examining those assumptions and practices that excluded considerations of difference in the first place. They take as self-evident the identities of those whose experience is being documented and thus naturalize their difference. They locate resistance outside its discursive construction and reify agency as an inherent attribute of individu- 
als, thus decontextualizing it... Questions about the constructed nature of experience, about how subjects are constituted as different in the first place,... are left aside. The evidence of experience then becomes evidence for the fact of difference, rather than a way of exploring how difference is established, how it operates, how and in what ways it constitutes subjects who see and act in the world.

Scott's (1991) meta-analysis of how meanings are made in history parallels Rose's (1998) insistence that the psy disciplines cannot be taken at their word, since they have helped to construct the language in which we speak subjectivity. These lessons from the humanities have still to be taken seriously. The constructed nature of identity categories themselves, the way difference is made to do the work of meaning-making from within the terms of the dominant system, these things are elided by the reinscription of binary categories: privileged/marginalized; oppressor/ oppressed. Here, we see the pull toward the construction of another binary, mentioned in Chap. 1, where material reality (suffering, exclusionary practices, actual violence) is placed against theory, the desire for meta-analysis of the meaning-making processes that underlie and enable the material suffering. My point, of course, is that they are complicit in each other, not at odds. Material reality is created by discourse, by power dynamics, by the meanings made of difference. And within, between, seeping outside of these processes, human being exceeds the binary positions imposed on it by systems of power, by history, by inheritance. If this were not true, what would be the point of therapy? Identity positions may be necessary to begin the work of resistance, but if they are also the end point, the system remains in place.

Lorde (1981) comments on being told she speaks with "the moral authority of suffering" because she is black and lesbian. Her response is, "what you hear in my voice is fury, not suffering. Anger, not moral authority. There is a difference." She details the importance of anger when there is injustice and suffering, where there is hatred of the difference represented by othered groups: "This hatred and our anger are very different. Hatred is the fury of those who do not share our goals [of liberation], and its object is death and destruction. Anger is a grief of distortions 
between peers, and its object is change." She asks for the creative, empowering use of anger to generate an ability to engage with difference, "to alter those distortions which history has created around our difference. For it is those distortions which separate us. And we must ask ourselves: Who profits from all this?"

The system based on binary thinking, on misogyny, racism, cisgenderism, ableism, classism, colonialism, profits. Certain groups, for whom this system was developed, profit. But even those of us who profit are intersectional, and therefore subject to the system. And since binary logic is false and artificial, as I have explored, what seems to be pure profit is always complicit, vulnerable. To use Lorde's (1981) idea, anger can be a force to break the binary, to shift us out of relations of victims and oppressors, to make us all peers in human being. Individuality, neocolonial discursive and material structures, liberal rights, neoliberal pressures and the twenty-first century imperative to profit from your personhood are forces against which rage is appropriate. And a complicit take on these dynamics allows us to start with the evidence of the experience of these systems, but not to end there, which would return us to the same terms.

Lorde's (1981) wisdom, as usual, remains relevant to our complex times. She rejects the commodification of suffering, while claiming and harnessing her righteous anger. She denies that anger has to turn into the same kind of othering hatred that generated the suffering and the anger in the first place. She refuses the charge that being angry because of racism makes her problematic or destructive to any cause, and she rightly returns the responsibility to the white women who are rendered guilty or uncomfortable by her anger. She also refuses the charge of causing hopelessness or of collapsing into victimhood: she is speaking about the productive and empowering use of anger to address injustice, and the necessity of allies being able to hear and learn from this, not collapse in the face of it, as the privileged often tend to do. She (Lorde, 1981) asks, "What woman here is so enamored of her own oppression that she cannot see her heelprint upon another woman's face? What woman's terms of oppression have become precious and necessary to her as a ticket into the fold of the righteous, away from the cold winds of self-scrutiny?"

I do not mean to minimize the real suffering caused by structural oppression. But I do mean to humbly and respectfully ask that we begin 
to consider our mutual entanglements in this structure. We are all complicit in each other. And if therapy nowadays can help, it can benefit enormously from getting away from reified truths.

\section{The Complicit Therapist: How Therapy Heals}

"[I]f we want to create a world in which conflict and trauma aren't the center of our collective existence, we have to practice something new, ask different questions, access again our curiosity about each other as a species" (brown 2020, p. 73). brown is talking specifically about the tendency in restorative and social justice movements to act against each other from the places of wounding caused by being the victims and survivors of histories of oppression and the systems of supremacy these histories continue to construct and fuel. This is an example of complicity, where allies are unconsciously driven by the methods they cannot help but have internalized as a result of being subject to them, subjected by them. Naming this, as brown does, is the necessary first step to finding ways to be different. We have to practice something new. But as a career in the humanities taught me via the theory I learned there, we will practice whatever the content of our common sense is. Common sense is always invested, always historically and politically produced. And it will always present itself as natural, obvious, the best and/or only way to think about things. This book has presented a way of thinking that tries to interrupt some of the common sense of Western culture: that binary thinking is inevitable, that we are not psychically and biologically co-created. If human being can be thought of as complicitous, we can open up to changes to our systems and ourselves, as the two will always influence each other.

We have looked at some psychotherapeutic approaches that, in their various ways, are systems oriented but also allow for a depth approach. I have added a focus on the necessity of a nonbinary understanding of how these dynamics work. The system is always nested in, and woven into, other systems: the individual is a system physiologically connected to their past, to their community, and to their caregivers and family, and all their systems in turn. Our parts are forged in these relationships, experiences, inheritances. The therapeutic dyad is also a system, made up of therapist 
and client co-creating their intersubjective third space, which itself holds all the nested systems, including the social-political inheritances and burdens at play in each unique space. The work of the therapeutic bond is neurobiological and an experience of deep human connection (Geller \& Porges, 2014), poetic in its inability to be accounted for scientifically outside of affective, embodied experience. Brains, minds, bodies, hearts and souls, we are connected. Therapy heals through complicity.

\section{Works Cited}

Afford, P. (2020). Therapy in the age of neuroscience. Routledge.

Anderson, F. G. (2013). "Who's taking what?" Connecting neuroscience, psychopharmacology and internal family systems for trauma. In M. Sweezy \& E. L. Ziskind (Eds.), Internal family systems: New dimensions (pp. 107-126). Routledge.

Badenoch, B. (2008). Being a brain-wise therapist: A practical guide to interpersonal neurobiology. Norton.

Benjamin, J. (1988). The bonds of love: Psychoanalysis, feminism and the problem of domination. Random House.

Benjamin, J. (1995). Like subjects, love objects: Essays on recognition and sexual difference. Yale University Press.

Bernheimer, C., \& Kahane, C. (Eds.). (1985). In Dora's case: Freud - hysteriafeminism (2nd ed.). Columbia University Press.

Binkley, S. (2020). Black rage and white listening: On the psychologization of racial emotionality. In D. M. Goodman, E. R. Severson, \& H. Macdonald (Eds.), Race, rage, and resistance: Philosophy, psychology, and the perils of individualism (pp. 90-107). Routledge.

Böckler, A., Herrmann, L., Trautwein, F., Holmes, T., \& Singer, T. (2017). Know thy selves: Learning to understand oneself increases the ability to understand others. Journal of Cognitive Enhancement, 1(2), 197-209.

Boonzaier, F., \& van Niekerk, T. (Eds.). (2019). Decolonial feminist community psychology. Springer.

Bretherton, I. (1992). The origins of attachment theory: John Bowlby and Mary Ainsworth. Developmental Psychology, 28, 759-777.

brown, a.m. (2020). We will not cancel us: and other dreams of transformative justice. AK Press.

Brown, L. (2018). Feminist therapy (2nd ed.). American Psychological Association. 
Brown, W. (1995). States of injury: Power and freedom in late modernity. Princeton University Press.

Butler, J. (1993). Imitation and gender insubordination. In H. Abelove, M. A. Barale, \& D. Halparin (Eds.), The gay and lesbian studies reader (pp. 307-320). Routledge.

Butler, J. (1997). The psychic life of power: Theories in subjection. Stanford University Press.

Coelho, N. E., \& Figueiredo, L.C. (2003). Patterns of intersubjectivity in the constitution of subjectivity: Dimensions of otherness. Culture \& Psychology, 9(3), 193-208.

Collins, L. H., Machizawa, S., \& Rice, J. K. (Eds.). (2019). Transnational psychology of women: Expanding international and intersectional approaches. American Psychological Association.

Cooper, S. H. (2007). Begin the Beguine: Relational theory and the pluralistic third. Psychoanalytic Dialogues, 17(2), 247-271.

Cozolino, L. (2010). The neuroscience of psychotherapy: Healing the social brain (2nd ed.). Norton.

Dankoski, M. E., \& Deacon, S. A. (2000). Using a feminist lens in contextual therapy. Family Process, 39(1), 51-66.

Drescher, J., Schwartz, A., Casoy, F., McIntosh, C. A., Hurley, B., Ashley, K., Barber, M., Goldenberg, D., Herbert, S. E., Lothwell, L. E., Mattson, M. R., McAfee, S. G., Pula, J., Rosario, V., \& Tompkins, A. D. (2016). The growing regulation of conversion therapy. Journal of Medical Regulation, 102(2), 7-12.

Foucault, M. (1977). Discipline and punish: The birth of the prison. Trans. A. Sheridan. Random House.

Gamson, J. (1995). Must identity movements self-destruct? A Queer Dilemma. Social Problems, 42(3), 390-407.

Geller, S., \& Porges, S. (2014). Therapeutic presence: Neurophysiological mechanisms mediating feeling safe in therapeutic relationships. Journal of Psychotherapy Integration, 24(3), 178-192.

Goodman, D., \& Freeman, M. (Eds.). (2015). Psychology and the other. Oxford University Press.

Goulding, R. A., \& Schwartz, R. C. (2003). The mosaic mind: Empowering the tormented selves of child abuse survivors. Trailheads Publications.

Greenspan, M. (2017). Feminism, therapy, and changing the world. Women \& Therapy, 40(3-4), 334-345.

Haddock, S. A., Weiler, L. M., Trump, L. J., \& Henry, K. L. (2016). The efficacy of internal family systems therapy in the treatment of depression among female college students: A pilot study. Journal of Marital and Family Therapy, 43(1), 131-144. 
Hare-Mustin, R. (1978). A feminist approach to family therapy. Family Process, $17,181-194$.

Harris, A. (2009). Gender as soft assembly. Routledge.

Herman, J. (1997). Trauma and recovery: The aftermath of violence - From domestic abuse to political terror. Basic.

Karen, R. (1994). Becoming attached: First relationships and how they shape our capacity to love. Oxford University Press.

Kurtz, R. (2007). Body-centered psychotherapy: The Hakomi method (Rev. ed.). LifeRhythm.

Langer, S. J. (2019). Theorizing transgender identity for clinical practice: A new model for understanding gender. Jessica Kingsley.

Levine, P. (1997). Waking the tiger: Healing trauma. North Atlantic.

Levine, P. A. (2018). Polyvagal theory and trauma. In S. Porges \& D. Dana (Eds.), Clinical applications of the polyvagal theory: The emergence of polyvagalinformed therapies (pp. 3-26). Norton.

Lorde, A. (1981). The uses of anger. BlackPast. Retrieved March 9, 2021, from https://www.blackpast.org/african-american-history/speeches-africanamerican-history/1981-audre-lorde-uses-anger-women-responding-racism/

Lucero, R., Jones, A. C., \& Hunsaker, J. C. (2018). Using Internal Family Systems theory in the treatment of combat veterans with Post-Traumatic Stress Disorder and their families. Contemporary Family Therapy, 40, 266-275. Matheson, J. (2015). IFS, an evidence-based practice. Foundation for Self Leadership. Retrieved February 22, 2021, from http://www.foundationifs. $\mathrm{org} /$ news-articles/79-ifs-an-evidence-based-practice

McGilchrist, I. (2009). The master and his emissary: The divided brain and the making of the Western world. Yale University Press.

Newhook, J. T., Pyne, J., Winters, K., Feder, S., Holmes, C., Tosh, J., Sinnott, M., Jamieson, A., \& Pickett, S. (2018). A critical commentary on follow-up studies and "desistance" theories about transgender and gender-nonconforming children. International Journal of Transgenderism, 19(2), 212-224.

Ogden, P. (2018). Polyvagal theory and sensorimotor psychotherapy. In S. Porges $\&$ D. Dana (Eds.), Clinical applications of the polyvagal theory: The emergence of polyvagal-informed therapies (pp. 34-49). Norton.

Payne, P., Levine, P. A., \& Crane-Godreau, M. A. (2015, February 4). Somatic experiencing: Using interoception and proprioception as core elements of trauma therapy. Frontiers in Psychology. Retrieved January 2, 2021, from https://www.frontiersin.org/articles/10.3389/fpsyg.2015.00093/full\#h6

Peña, J. (2019). The embodied intersubjective space: The role of clinical intuition in somatic psychotherapy. Body, Movement and Dance in Psychotherapy, 14(2), 95-111. 
Porges, S. (2018). Polyvagal theory: A primer. In S. Porges \& D. Dana (Eds.), Clinical applications of the polyvagal theory: The emergence of polyvagal-informed therapies (pp. 50-72). Norton.

Robbins, J. H. (1995). Making changes. In E. F. Williams (Ed.), Voices of feminist therapy (pp. 61-70). Harwood.

Rose, N. (1998). Inventing our selves: Psychology, power and personhood. Cambridge University Press.

Sang, B. E. (1995). Going around in circles and coming out in the same place and different places - My development as a feminist therapist. In E. F. Williams (Ed.), Voices of feminist therapy (pp. 39-49). Harwood.

Schore, A. (2003). Affect dysregulation and disorders of the self. Norton.

Schore, A. (2012). The science of the art of psychotherapy. Norton.

Schwartz, R. C. (2013). The therapist-client relationship and the transformative power of Self. In M. Sweezy \& E. L. Ziskind (Eds.), Internal family systems: New dimensions (pp. 1-23). Routledge.

Schwartz, R. C. (2017). Dealing with racism: Should we exorcise or embrace our inner bigots? In M. Sweezy \& E. Ziskind (Eds.), Innovation and elaborations in Internal Family Systems therapy (pp. 124-132). Routledge.

Schwartz, R. C., \& Sweezy, M. (2020). Internal Family Systems therapy (2nd ed.). Guilford.

Scott, J. W. (1991). The evidence of experience. Critical Inquiry, 17(4), 773-797. Sehrbrock, J. (2020). Social thirdness: Intersubjective conceptions of the experience of gender prejudice. Psychoanalysis, Self and Context, 15(3), 289-295.

Siegel, D. (2003). An interpersonal neurobiology of psychotherapy. In M. F. Solomon \& D. Siegel (Eds.), Healing Trauma: attachment, mind, body and brain (pp.1-56). New York and London: Norton.

Siegel, D. J. (1999). The developing mind: How relationships and the brain interact to shape who we are. Guilford.

Siegel, D. J. (2007). The mindful brain. Norton.

Siegel, D. J. (2019). The mind in psychotherapy: An interpersonal neurobiology framework for understanding and cultivating mental health. Psychology and Psychotherapy: Theory, Research and Practice, 92, 224-237.

Solomon, M. F., \& Siegel, D. J. (Eds.). (2003). Healing trauma: Attachment, mind, body, brain. Norton.

Sowell, N. (2013). The internal family system and adult health: Changing the course of chronic illness. In M. Sweezy \& E. L. Ziskind (Eds.), Internal family systems: New dimensions (pp. 127-142). Routledge.

Stephens, M. (2020). Getting next to ourselves: The interpersonal dimensions of double-consciousness. Contemporary Psychoanalysis, 56(2-3), 201-225. 
Stern, D. (1985). The interpersonal world of the infant. Basic.

Sugarman,J.(2020). Neoliberalismand theethicsofpsychology.InD.M.Goodman, E. R. Severson, \& H. Macdonald (Eds.), Race, rage, and resistance: Philosophy, psychology, and the perils of individualism (pp. 73-89). Routledge.

Sweezy, M., \& Ziskind, E. (Eds.). (2017). Innovation and elaborations in Internal Family Systems therapy. Routledge.

Van der Kolk, B. (2014). The body keeps the score: Mind, brain and body in the healing of trauma. Penguin.

Van der Kolk, B. (2018). Safety and reciprocity: Polyvagal theory as a framework for understanding and treating developmental trauma. In S. Porges \&

D. Dana (Eds.), Clinical applications of the polyvagal theory: The emergence of polyvagal-informed therapies (pp. 27-33). Norton.

Williams, E. F. (Ed.). (1995). Voices of feminist therapy. Harwood.

Zerbe Enns, C., Bryant-Davis, T., \& Comas Díaz, L. (2020). Transnational feminist therapy: Recommendations and illustrations. Women \& Therapy. Retrieved January 27, 2021, from https://doi.org/10.1080/02703149.2020.1776021

Open Access This chapter is licensed under the terms of the Creative Commons Attribution 4.0 International License (http://creativecommons.org/licenses/ by/4.0/), which permits use, sharing, adaptation, distribution and reproduction in any medium or format, as long as you give appropriate credit to the original author(s) and the source, provide a link to the Creative Commons licence and indicate if changes were made.

The images or other third party material in this chapter are included in the chapter's Creative Commons licence, unless indicated otherwise in a credit line to the material. If material is not included in the chapter's Creative Commons licence and your intended use is not permitted by statutory regulation or exceeds the permitted use, you will need to obtain permission directly from the copyright holder.

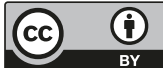

